\title{
A Broader View of Risk Management Process in Projects
}

\author{
Zoltán Sebestyén ${ }^{1}$ and Tamás Tóth ${ }^{2}$
}

1 Budapest University of Technology and Economics, Budapest, Hungary, sebestyen@mvt.bme.hu

2 Eötvös Loránd University, Budapest, Hungary, totht@gti.elte.hu

\begin{abstract}
Risks have to be managed with great care so that the final goal of delivering a successful project can be reached. The paper extends the risk management process with the value-based risk monitoring framework developed by the authors, where the primary purpose is to detect and monitor risks jeopardizing the expected project return, and if necessary, to start action plans in order to avoid losses. An important characteristic of the suggested integrated model is that it takes into consideration that risks are timevarying, that is, as time passes, the uncertainty of the occurrence of a risk changes. In this paper, the traditional risk management process is extended with the value-based approach, where risk factors are measured on a linear scale. The integrated project risk management process supports the organizationlevel decision making, and extends the fundamental roles of project portfolio management office identified by the literature.
\end{abstract}

(c) 2020 The Authors. Published by Budapest University of Technology and Economics \& Diamond Congress Ltd Peer-review under responsibility of the Scientific Committee of the Creative Construction Conference 2020.

Keywords: integrated methods, project risk management, risk management process

\section{Introduction}

Project risk management is about controlling unexpected issues that might affect the level of activities in the project, or the whole project itself. Project risk management became one of the most important aspects of project management so much so that significant international organizations issued standards on it (e.g., [1]). Risk management is one of the ten competency areas in the PMI's PMBoK (Project Management Institute's Guide to the Project Management Body of Knowledge). Project risk is defined by the PMI's risk management standard as, "an uncertain event or condition that, if it occurs, has a positive or negative effect on a project's objectives." [1]

Risks have an inherent uncertainty, their occurrence is not predestined, so they have to be managed with great care. The ultimate goal of project risk management is to achieve project success. There are several issues of project success [2] that are not subject to investigation in this study. To achieve this goal, the risk management process has to serve the optimization of risks. The optimization process is responsible for balancing the probabilities and both the positive and negative impacts of risks. According to the PMBoK, a well balanced portfolio of risk requires the following steps: Planning Risk Management, Identifying Risks, Qualitative Risk Analysis, Quantitative Risk Analysis, Planning Risk Responses, Implementing Risk Responses, and Monitoring Risks [3].

The current study focuses on integrating risk management into a common risk management process. There are three principles of the proposed risk management framework. On the one hand, the suggested model takes into account the minimum requirements of the owner. On the other hand, the model has to be able to operate and perform evaluation in the whole life cycle of the project, not only in the first, risk management phase. Furthermore, it is important that the evaluation process can be conducted easily in practice without solid financial knowledge. 
Firstly, there is a brief survey on the traditional, category-based literature. Secondly, after this review of the traditional project risk management approaches, the process is presented with suggestions for the extension. In this section, there are recommendations how to integrate the traditional process with the value-based model. Finally, the fundamentals of the developed model are summarized.

\section{Traditional project risk management concepts}

The prevailing concept of risk management is about risk classification. The traditional risk management methods are widely presented in the literature [4], [5], moreover, there are numerous industrial applications [6]-[8]. The general purpose of comprehensive project risk management is to mitigate the risks with categorization [9], [10]. Project risk management has been an area targeted by researchers from the 1950's. In the last decades, subjective elements of risks have gained more and more attention [11], [12]. Obviously, the objective, quantitative side of project risk management still remained the most intensively researched area. Derived from the traditional risk classification concept, mathematical models, such as various probabilistic (e.g., [13]-[15]), and deterministic approaches (e.g., [16]) the analytic hierarchy process (e.g., [17]), fuzzy approximation and composition (e.g., [18]), artificial neural networks (e.g., [19]), Bayesian networks (e.g., [20],), and Markov modelling (e.g., [21]) are developed and applied to risk assessment.

For a while, integration efforts concerning project management and other professional areas appeared, reference [22] has successfully established a relevant relationship between risk management and project management, but the time for the synthesis with other distant fields has not yet come.

The paper extends the risk management process with the value-based risk monitoring framework developed by Tóth and Sebestyén [23], where the primary purpose is to detect and monitor risks jeopardizing expected project return, and if necessary, to start action plans in order to avoid losses. An important characteristic of the suggested integrated model is that it takes into consideration that risks are time-varying, that is, as time passes, the uncertainty of the occurrence of a risk changes [24]. The traditional risk management process is extended with the value-based approach, where risk factors are measured on a linear scale.

\section{Integrated project risk management concept}

From a financial aspect, the goal of a project is to achieve a higher expected internal rate of return than is possible from capital market investments with similar relevant risk. Lately, it has turned out that there are other several industry-specific objectives besides the financial ones, and these can be even more important [25].

To introduce a new approach to traditional category-based risk management from the area of the theory of finance, the harmful events must be identified. These harmful events are the financial bottlenecks, and have a negative impact on the project. On the one hand, the organization must be liquid, and has to maintain a positive cash flow $\left(L_{t}\right)$ in each year $(t) .(1)$

$$
L_{t}=g\left(x_{1, t}, \ldots, x_{n, t}, \ldots, x_{N, t}\right) \geq 0 \quad \forall t \in[0, T]
$$

$n=(1, \ldots, N)$ refers to the nature of the parameter, and $t=(1, \ldots, T)$ refers to the given time period in years. On the other hand, the debt service coverage ratio $\left(D S C R_{t}\right)$ cannot decrease below the value $\left(C_{t}\right)$ that is specified by the loan contract in each year. (2)

$$
D S C R_{t}=v\left(x_{1, t}, \ldots x_{n, t}, \ldots, x_{N, t}\right) \geq C_{t} \quad \forall t \in[0, T]
$$

The integrated model concentrates on one of the three typical harmful events. Firstly, the expected internal rate of return or the economic internal rate of return is less than or equal to the minimum requirements of the owners. Secondly, the yearly cash balance is negative. Thirdly, the yearly debt service coverage ratio is less than the specified value. 


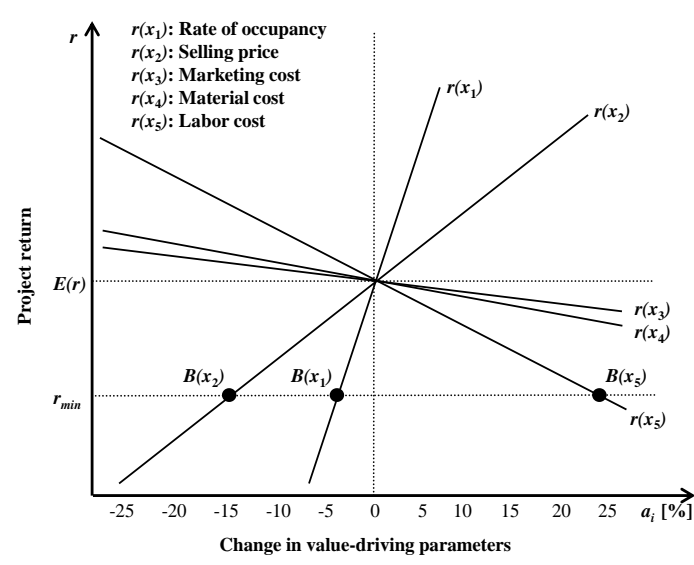

Fig. 1. Sensitivity analysis

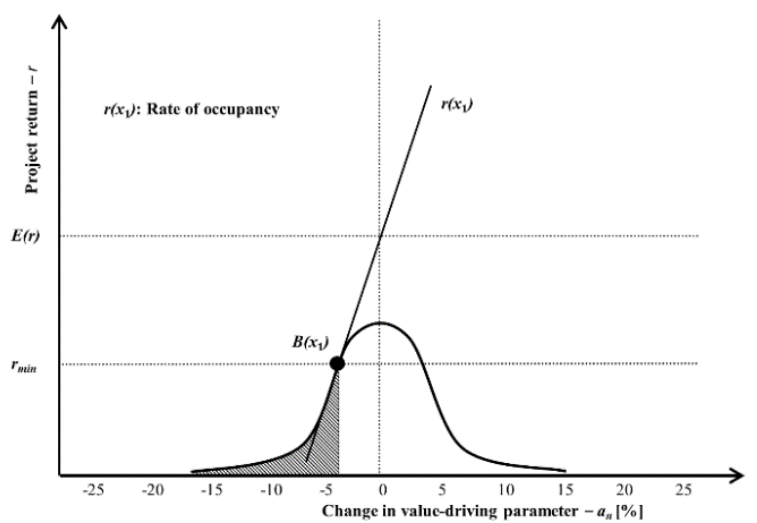

Fig. 2. Probability of the occurrence of a harmful event

In the integrated approach, risk management is based on the financial valuation of the project, and the risks are measured by the probability of the occurrence of critical deviance of the value-driving parameters from their expected values calculated in the planning phase of the project. This is the principle of the valuebased financial risk management process [26]. Value-driving parameters become critical, when their deviations result in zero or negative NPV to the owners. The aim of risk monitoring is to follow some selected value-driving parameters and when they are in the intervention zone, launch the predefined action plans to restore the normal value-making process, and to reinitialize the business model. Risk analysis is a continuous process during the whole life cycle of the project. The value-driving parameters are in the focus of the integrated process. Value-driving parameter $\left(x_{n, t}\right)$ can be any arbitrary variable that can have any effect on the financial condition of the owners of the project.

The economic break-even point $\left(B\left(x_{n}\right)\right)$ is the critical value of each value-driving parameter that can be determined (3).

$$
N P V=\sum_{t=0}^{T} \frac{s\left(x_{1, t}, \ldots, x_{n, t}\left(1+B\left(x_{n}\right)\right), \ldots, x_{N, t}\right)}{(1+r)^{t}}=0
$$

where $r$ refers to the cost of invested capital, $B\left(x_{n}\right)$ expresses the changes of parameter $x_{n}$ that occurs evenly in every year, which makes the project's net present value equal zero. That is, a larger change in the value of $x_{n}$ makes the project value-destroying.

The breakeven point $B\left(x_{n}\right)$ is a point of reference in the calculation of the probability that changes in parameter $x_{n}$. The question is how to find the region where the value-driving parameters are larger than $B\left(x_{n}\right)$. In this case, this component becomes value-destroying, and more attention should be paid by the management. In this region, the value driving parameters may be responsible for the poor performance. Based on Fig. 1 [27], the sensitivity analyses can be conducted to select the relevant value-driving parameters describing the project's total risk the best.

Based on Fig. 1, the occurrence of a harmful event can be determined. If the probability distribution function is identified properly, the probability of the value-driving parameter becoming value destroying is calculated. If the probability density function of occupancy $\left(f\left(x_{1}\right)\right)$ is known, by integrating over minus infinity to $B\left(x_{1}\right)$, one can determine the probability $(P)$ that the value of the value-driving variable is less than the break-even point (7). Thus, the variable deviates sufficiently in the negative direction to render the project value-destroying. Finally, retrieving the probability of becoming harmful to the project is the ultimate aim of this process. Let us assume that the random variable follows normal distribution in Fig.2. [28] The probability when changes in parameter $x_{n}$ are over $B\left(x_{n}\right)$ is calculated by Equation (4). The project manager is interested in the probability that changes in parameter $x_{n}$ are larger than $B\left(x_{n}\right)$. 


$$
P\left(-\infty<a_{n} \leq B\left(x_{n}\right)\right)=\int_{-\infty}^{B\left(x_{n}\right)} f\left(x_{n}\right) d x_{n}
$$

\section{Extending traditional project risk management process}

Let us consider the traditional risk management process, review the basic steps, and complete the process based on the integrated concept after an evaluation.

In the PMI's standard work the integrated risk management of the projects are part of an organization's portfolio (or program) [3]. The owners and the managers of risks are at different levels and are in various clusters of projects. Certain risks are within the boundaries of the project, some others lie outside the project, but still inside the organization, and there are ones outside the organization. These risks must be identified and handled at the right level, and by the proper risk owner. The point in managing projects in an integrated way is to gain the highest value for a level of risk exposure, that is, the positive effects of risks should exceed the negative ones. Here it must be emphasized that the risk owner is not the owner of the project, and they have different interpretations. In our suggestion, the owner has as special a role in project risk management as in the theory of finance. Therefore, in the integrated concept, the extensions of the risk management process are based on the owner itself.

\subsection{Plan Risk Management}

In the Plan Risk Management phase, the risk management method must be selected along with the risk itself, and how important it is to the stakeholders and participants. All the subsidiary risk plans must conform to the global project risk management plan. The degree, the type, and the visibility of risk management are defined by the scope of the process and who are involved in it. The planning process is affected by the integrated risk model. New types of risk assessment points must be scheduled, which will be part of the risk management plan. As the PMI (2017) states, the risk appetite of stakeholders including the owner is recorded in the risk management plan [3]. The appetite for risk is quantifiable and measurable. The integrated model is in line with this condition.

\subsection{Identify risks}

In the phase of Identify Risks, all the individual and global risks are identified and documented. The organization reveals the sources of overall project risks. The identification process is a continuous activity during the whole life cycle of the project. All project stakeholders are encouraged to introduce new individual or global risk sources into the risk management process. The PMI (2017) highlights project manager, project team members, project risk specialist, customers, external experts from application area, end user, operations managers, stakeholders, risk management experts as relevant stakeholders [3]. There is no doubt that these participants have an important role in project risk management, yet the owner's significance is not outlined, as the integrated model is based on the owner's risk appetite via its minimum requirement. The risk register, which contains a list of risks with their size and complexity, differentiates the causes and effects of risks. To list the risk in the register ensuing from the owner's risk appetite is recommended.

\subsection{Perform Qualitative Risk Analysis}

The phase Perform Qualitative Risk Analysis is responsible for ranking project risks. The ranking process can be conducted in many ways, organizations even possess their own special methods, but all the methods are built on the assessment of probability of occurrence and the impact on the project. There is no difference between the principles of qualitative and quantitative methods in this sense. This process has to rank the risks by weighting the impacts with the probabilities using soft methods. One of the most important step of this process is risk categorization. Recently, widely used project risk management methods apply risk categories to identify the most important risk sources. Categorization can be conducted in several ways, finding common characteristics or root causes. Once a group of risks with the highest exposure is identified, greater attention can be paid to it. The Probability and impact matrix, and the Hierarchical charts are typical category-based tools for risk management. The Probability and impact matrix 
can be created for each objective. The matrix helps graphically to categorize the risks into groups in the dimensions of probability of occurrence and impact. If the categorization is conducted by three dimensions, the two dimensional matrix is insufficient. Hierarchical charts display risks in two dimensions by the two axes, but the size of a graphical figure (usually disks, bubbles) represents a third dimension (e.g., acceptance level).

\subsection{Perform Quantitative Risk Analysis}

The multi-dimensional concept of qualitative risk analysis underlies the phase Perform Quantitative Risk Analysis. On the one hand, this phase is optional, on the other hand, the analysis is numerical here. Quantitative risk analysis enables a reliable evaluation of risks. Frequently, the quantitative process is required by decision-maker stakeholders. The prerequisite of this assessment is the availability of relevant, quantifiable ratio scale data. A fundamental question in this phase is how to analyze the collected data. The analysis is usually based on simulation that determines the effects of risks, sensitivity analysis, or decision tree analysis. In a special sense, the integrated risk assessment method is in accordance with the phase of qualitative risk analysis. Therefore, the integrated risk management process must be conducted in this phase. The categorization of risks is a typical step for performing quantitative or qualitative risk analysis. Let us refer to two up-to-date cases of how researchers established a sophisticated risk management model with risk categories.

\subsection{Final phases}

In the phase Plan Risk Responses, to address project risks, activities for the plan and documents had to be defined. The responses include reviewing options, choosing strategies, and triggering actions. Properly selected responses are responsible for exploiting opportunities, and reducing threats stemming from risks. The project team including project manager selects the sufficiently important project risks, and gives the appropriate response. The appropriate response can be selected from a set of strategies. It is important to understand what the effects of the risk in question can be. If there are threatening effects, the project manager can escalate, avoid, transfer, mitigate, or accept it. If there are opportunities, very similar tools are to be employed: escalate, exploit, share, enhance, and accept. The last two steps are the phases of Implementing Risk Responses and Monitoring Risks.

\section{Conclusion}

To deliver successful projects, project risk management seems inevitable. The paper introduces the concept of an integrated project risk management process that takes an unusual aspect into consideration. The fundamentals of the model are introduced and presented. This study extends the risk management process, describes what the phases of the project risk management process are, and how to conclude the assessment with the value-based risk monitoring framework developed by the authors. In this paper, the traditional risk management process is extended with the value-based approach, where risk factors are measured on a linear scale. The suggested model handles the time-varying feature of risks as well, namely, the uncertainty of the occurrence of a risk changes as time passes.

\section{References}

[1] Project Management Institute, Practice Standard for Project Risk Management. Project Management Institute, 2009.

[2] Z. Sebestyén, Further Considerations in Project Success, Procedia Engineering, vol 196 (2017) pp. 571-577. https://doi.org/10.1016/j.proeng.2017.08.032.

[3] Project Management Institute, A guide to the project management body of knowledge (PMBOK guide), Sixth Edit. Newtown Square, Pennsylvania: Project Management Institute, 2017.

[4] R.J. Turner, The handbook of project-based management Improving the processes for achieving strategic objectives, 2nd ed. London: McGraw-Hill, 1999.

[5] D. Baloi, A.D.F. Price, Modelling global risk factors affecting construction cost performance, International Journal of Project Management, vol 21, no 4 (2003) pp. 261-269. https://doi.org/10.1016/S0263-7863(02)00017-0.

[6] M. Bevilacqua, F.E. Ciarapica, G. Giacchetta, Critical chain and risk analysis applied to high-risk industry maintenance: A case study, International Journal of Project Management, vol 27, no 4 (2009) pp. 419-432. https://doi.org/10.1016/j.ijproman.2008.06.006.

[7] C.-L. Hwang, K. Yoon, Methods for Multiple Attribute Decision Making, in Multiple Attribute Decision Making: Methods and Applications A State-of-the-Art Survey, Springer-Verlag Berlin Heidelberg, 1981, pp. 58-191. https://doi.org/10.1007/978-3-64248318-9_3. 
[8] D.W.M. Chan, A.P.C. Chan, P.T.I. Lam, J.F.Y. Yeung, J.H.L. Chan, Risk ranking and analysis in target cost contracts: Empirical evidence from the construction industry, International Journal of Project Management, vol 29, no 6 (2011) pp. 751-763. https://doi.org/10.1016/j.jproman.2010.08.003.

[9] R. Flanagan, G. Norman, Risk management and construction, Blackwell Scientific Oxford, (1993) p. 208.

[10] A. Klemetti, Risk Management in Construction Project Networks, Helsinki University of Technology, 2006.

[11] E.C. Alexopoulos, Z. Kavadi, G. Bakoyannis, S. Papantonopoulos, Subjective risk assessment and perception in the Greek and English bakery industries, Journal of Environmental and Public Health, vol 2009 (Oct. 2009) p. 891754. https://doi.org/10.1155/2009/891754.

[12] M.C.Y. Au, E.H.W. Chan, Attitudes of Contractors and Employers Towards Transfer of a Time-Related Risk in Construction Contracts, in Construction Research Congress 2005, 2005, pp. 1-13. https://doi.org/10.1061/40754(183)68.

[13] M. Hajdu, O. Bokor, Sensitivity analysis in PERT networks: Does activity duration distribution matter?, Automation in Construction, vol 65 (May 2016) pp. 1-8. https://doi.org/10.1016/j.autcon.2016.01.003.

[14] A. Purnus, C.-N. Bodea, Project Prioritization and Portfolio Performance Measurement in Project Oriented Organizations, Procedia Social and Behavioral Sciences, vol 119 (2014) pp. 339-348. https://doi.org/10.1016/j.sbspro.2014.03.039.

[15] B. Mulholland, J. Christian, Risk Assessment in Construction Schedules, Journal of Construction Engineering and Management, vol 125, no 1 (Jan. 1999) pp. 8-15. https://doi.org/10.1061/(ASCE)0733-9364(1999)125:1(8).

[16] C. Muriana, G. Vizzini, Project risk management: A deterministic quantitative technique for assessment and mitigation, International Journal of Project Management, vol 35, no 3 (2017) pp. 320-340. https://doi.org/10.1016/j.ijproman.2017.01.010.

[17] A. Nieto-Morote, F. Ruz-Vila, A fuzzy approach to construction project risk assessment, International Journal of Project Management, vol 29, no 2 (2011) pp. 220-231. https://doi.org/10.1016/j.jproman.2010.02.002.

[18] S.J. Hosseininezhad, M.S. Jabalameli, S.G.J. Naini, A fuzzy algorithm for continuous capacitated location allocation model with risk consideration, Applied Mathematical Modelling, vol 38, no 3 (Feb. 2014) pp. 983-1000. https://doi.org/10.1016/j.apm.2013.07.006.

[19] X. Jin, G. Zhang, Modelling optimal risk allocation in PPP projects using artificial neural networks, International Journal of Project Management, vol 29, no 5 (2011) pp. 591-603. https://doi.org/10.1016/j.jproman.2010.07.011.

[20] V. Khodakarami, A. Abdi, Project cost risk analysis: A Bayesian networks approach for modeling dependencies between cost items, International Journal of Project Management, vol 32, no 7 (2014) pp. 1233-1245. https://doi.org/10.1016/j.jproman.2014.01.001.

[21] R. Espada Jr., A. Apan, K. McDougall, Spatial modelling of natural disaster risk reduction policies with Markov decision processes, APPLIED GEOGRAPHY, vol 53 (2014) pp. 284-298. https://doi.org/10.1016/j.apgeog.2014.06.021.

[22] E. Rodney, Y. Ducq, D. Breysse, Y. Ledoux, An integrated management approach of the project and project risks, IFACPapersOnLine, vol 28, no 3 (2015) pp. 535-540. https://doi.org/10.1016/j.ifacol.2015.06.136.

[23] T. Toth, Z. Sebestyen, Project risk management process for professionals: A value-based approach. 2017, https://doi.org/10.4018/978-1-5225-3932-2.ch015.

[24] T. Toth, Z. Sebestyen, Time-varying Risks of Construction Projects,, in Procedia Engineering, 2015, vol 123, pp. 565-573. https://doi.org/10.1016/j.proeng.2015.10.109.

[25] I. Szilágyi, Z. Sebestyén, T. Tóth, Project Ranking in Petroleum Exploration, The Engineering Economist, (2019) pp. 1-22. https://doi.org/10.1080/0013791X.2019.1593570.

[26] Z. Sebestyén, T. Tóth, A revised interpretation of risk in project management, Periodica Polytechnica, Social and Management Sciences, vol 22, no 2 (2014) https://doi.org/10.3311/PPso.7740.

[27] Z. Sebestyén, T. Tóth, Towards an integrated controlling tool based on a time-varying project risk management concept, IEEE International Conference on Industrial Engineering and Engineering Management, vol 2017-Decem (2017) pp. 720-724. https://doi.org/10.1109/IEEM.2017.8289985.

[28] T. Toth, Z. Sebestyen, Project risk management process for professionals: A value-based approach,, in Managing Project Risks for Competitive Advantage in Changing Business Environments, 1st ed., C.-N. Bodea, P. Augustin, H. Martina, and H. Miklós, Eds. IGI Global, 2016, pp. 128-149. https://doi.org/10.4018/978-1-5225-3932-2.ch015. 